\title{
Psychological and sociodemographic predictors
} of premature discontinuation of a I-year multimodal outpatient weight-reduction program: an attrition analysis

\author{
This article was published in the following Dove Press journal: \\ Patient Preference and Adherence \\ 6 March 2012 \\ Number of times this article has been viewed
}

\author{
Anne Ahnis' \\ Andrea RiedI' \\ Andrea Figura' \\ Elisabeth Steinhagen- \\ Thiessen ${ }^{2}$ \\ Max E Liebl ${ }^{3}$ \\ Burghard F Klapp' \\ 'Internal Medicine and Dermatology, \\ Medical Department, Division of \\ Psychosomatic Medicine, Charité - \\ Universitätsmedizin Berlin, Campus \\ Mitte, ${ }^{2}$ Internal Medicine with \\ Gastroenterology and Nephrology, \\ Specialty network of \\ Gastroenterology, Endocrinology \\ and Metabolic Diseases, Division \\ of Lipid Metabolism, Charité - \\ Universitätsmedizin Berlin, \\ Campus Virchow-Klinikum, \\ ${ }^{3}$ Medical Department, Division \\ of Rheumatology and Clinical \\ Immunology, Department for \\ Physical Medicine, Charité - \\ Universitätsmedizin Berlin, Campus \\ Mitte, Berlin, Germany
}

Objective: Attrition rates of up to $77 \%$ have been reported in conservative weight-reduction programs for the treatment of obesity. In view of the cost of such programs to the health system, there is a need to identify the variables that predict premature discontinuation of treatment. Previous studies have focused mainly on somatic and sociodemographic parameters. The prospective influence of psychological factors has not been systematically investigated to date.

Methods: A total of 164 patients (138 of whom were women) with a mean age of 45 years and a mean body mass index of 39.57 participated in a 1-year outpatient weight-reduction program at the Charité - Universitätsmedizin Berlin University Hospital. The program included movement therapy, dietary advice, psychoeducational and behavioral interventions, relaxation procedures, and consultations with a specialist in internal medicine and a psychologist. Patients also underwent regular laboratory and psychological testing. The results were evaluated using a $t$-test, $\chi^{2}$-test, and logistic regression analysis.

Results: Seventy-one of the 164 patients (61 women, mean age $=43$ years, mean body mass index $=39.53$ ) withdrew before the end of the program (attrition rate $=43.3 \%$ ). While there were no differences between the somatic and metabolic characteristics of those who withdrew and those who remained, the sociodemographic and psychological factors had some relevance. In particular, “expectation of self-efficacy” (Fragebogen zu Selbstwirksamkeit, Optimismus und Pessimismus [SWOP]), "not working," "tiredness" (Berliner Stimmungsfragebogen [BSF]), "pessimism" (SWOP) and "positive reframing" (Brief-COPE) were found to play a role in whether participants subsequently dropped out of the treatment. "Support coping" (Brief-COPE) and "older age" prior to the start of treatment were identified as variables that promoted treatment adherence.

Conclusion: The results are discussed in light of previous findings and with regard to whether the modules of the weight-reduction program should be adapted.

Keywords: obesity, weight-reduction program, attrition rate, dropouts, treatment adherence

\section{Introduction}

Obesity is a chronic disease associated with an increased risk of morbidity and mortality ${ }^{1}$ that is increasing worldwide. ${ }^{2}$ In Western Europe, approximately $20 \%$ of men and women are obese (body mass index $[\mathrm{BMI}] \geq 30 \mathrm{~kg} / \mathrm{m}^{2}$ ). ${ }^{2}$ There is evidence that intentional moderate weight loss (losses of 5\%-10\%) has long-term benefits for all causes of mortality for overweight $\left(\mathrm{BMI} \geq 25 \mathrm{~kg} / \mathrm{m}^{2}\right)$ and obese women, and more so for diabetics. ${ }^{3}$ Weight loss is usually associated with improvements in mental wellbeing, especially for symptoms of depression and anxiety. ${ }^{4}$
Charité - Universitätsmedizin Berlin Medizinische Klinik mit Schwerpunkt Psychosomatik, Luisenstrasse I3A, D-10117 Berlin, Germany

Tel +49 30/450553278

Fax +49 30/450553989

Email anne.ahnis@charite.de 
Treatment guidelines for obesity ${ }^{5-8}$ recommend a multimodal approach for the conservative treatment of obesity, consisting of a change in diet, modifications to dietary behavior, an increase in physical activity, and behavioral therapy interventions. $^{8}$

Multimodal conservative weight-reduction programs have been reported in Germany ${ }^{9-11}$ and several other countries..$^{12,13}$ While greater weight loss can be achieved and maintained with surgical solutions for obesity, ${ }^{6,14-17}$ only $5 \%-15 \%$ of patients with BMIs of $30-40 \mathrm{~kg} / \mathrm{m}^{2}$ respectively are able to maintain the weight loss they achieve through conservative treatment. ${ }^{18,19}$ Success rates for patients with BMIs higher than $40 \mathrm{~kg} / \mathrm{m}^{2}$ are even lower. ${ }^{20,21}$ These rates apply only to patients who actually complete the treatment, but some studies ${ }^{11,13,22,23}$ have shown that attrition rates for outpatient weight-reduction programs that last for 12 months or longer may be as high as $77.3 \%$.

It remains unclear why obese patients show lower therapy adherence. Table 1 includes the variables that have been examined in previous studies (adult patients with obesity and longer-term multimodal conservative weight-reduction programs [without pharmacotherapy for weight loss]).

The current review of the literature revealed that none of the studies that were analyzed reported details on psychological and behavioral factors. Furthermore, there are inconsistencies in the findings for the variables investigated (also note the recently published review of Moroshko et $\mathrm{al}^{24}$ ).

The aim of the current retrospective study was to identify the psychological variables that predicted premature discontinuation of a 1-year outpatient multimodal weightreduction program at the Charité - Universitätsmedizin Berlin University Hospital by using logistic regression analysis. The current study's data collection was based on a naturalistic design to evaluate the quality of the treatment program in a clinical setting. The evaluation procedure involved a variety of psychological, physical, and blood tests prior to the beginning of the program and during the course of the program. These evaluations allowed the range of previously studied somatic (such as BMI), ${ }^{9,10,12,13,25,26}$ sociodemographic (such as age and gender), ${ }^{9,10,12,13,23,25}$ psychological, and behavioral factors (such as depression, ${ }^{13,25}$ binge-eating disorders, ${ }^{25}$ and eating behavior ${ }^{13,25}$ ) to be expanded to include the following parameters: subjective resources, coping strategies, perceived stress, bodily complaints, mood, and quality of life.

Based on clinical impressions, in contrast to previous findings on depression, ${ }^{13,25}$ prior to the start of the program, it was assumed that those who dropped out of the program would have felt greater stress, showed higher scores for depression and anxiety, and had a lower quality of life than those who adhered to the program. It was assumed that those who dropped out would have fewer resources (lower scores for self-efficacy, optimism, and sense of coherence; higher scores for pessimism, and lower perceived emotional and instrumental social support) and more severely maladaptive processing modes (that is, higher scores for "avoidant coping" and "positive reframing," and lower scores for "support coping" and "active coping").

\section{Methods}

\section{Treatment program and data collection}

The 1-year multimodal outpatient program on which this study is based was at the Charité - Universitätsmedizin Berlin from December 2007, under an integrated health care contract (which ran until March 2011) with the German health insurance company Deutsche Angestellten Krankenkasse. The approved health insurance amount for the 1-year program was approximately $€ 2000$ and the patient's share was $€ 300$ (7\%). The program was divided into four areas of intervention and application: (1) movement therapy and training, (2) advice on diet and training, (3) psychoeducation and behavioral therapy interventions, and (4) Jacobson's progressive relaxation.

\section{Movement therapy and training}

Movement therapy was performed by trained physiotherapists with additional qualifications for equipment-based remedial gymnastics, aqua fitness, and medical workout therapy. Movement therapy was generally intended to invigorate the musculature and to enhance flexibility, physical condition, and coordination. Different methods of remedial gymnastics were applied. Participants were trained in basic physical properties, such as condition and coordination, as well as functional invigoration and stretching exercises for the main muscles. In addition, an exercise regimen was used to activate the metabolism and fat-burning abilities, with the goal of continually improving training times.

Within this therapy program, movement therapy primarily served to maintain weight following weight reduction through nutrition therapy. The goal was an increase of approximately 2-3 hours of exercise per week and an increase in energy consumption of at least $1500 \mathrm{kcal}$.

\section{Advice on diet and training}

Nutrition therapy was conducted by a dietician with additional qualifications in medical nutrition. Individual caloric requirements were evaluated prior to the program, based on the Deutsche Gesellschaft für Ernährung eV [German Nutrition Society], Österreichische Gesellschaft für 
Table I Variables of treatment dropout and adherence examined in previous studies

\begin{tabular}{|c|c|c|}
\hline $\begin{array}{l}\text { Variables identified as favoring } \\
\text { treatment dropout }\end{array}$ & $\begin{array}{l}\text { Variables showing inconsistent findings } \\
\text { between dropouts and adherents }\end{array}$ & $\begin{array}{l}\text { Variables showing no difference } \\
\text { between dropouts and adherents }\end{array}$ \\
\hline Full-time job ${ }^{13}$ & $\begin{array}{l}\text { Age } \\
\text { No difference }{ }^{9,10,13,25} \\
\text { Dropouts younger than adherents }\end{array}$ & Gender $9,10,13$ \\
\hline Fewer obesity-related diseases ${ }^{13}$ & $\begin{array}{l}\text { Baseline weights and baseline BMls } \\
\text { Higher baseline weights and BMls in dropouts } 9,25,26 \\
\text { Lower BMls in dropouts }^{13} \\
\text { No differences } \\
10,12\end{array}$ & Family status ${ }^{10,13}$ \\
\hline Lower age at first dieting ${ }^{23}$ & $\begin{array}{l}\text { Waist measurements } \\
\text { No difference } \\
\text { Lower waist circumference in dropouts }{ }^{13}\end{array}$ & Ethnicity (US studies) $)^{27}$ \\
\hline Lower dream BMI ${ }^{23}$ & $\begin{array}{l}\text { Depressiveness } \\
\text { No differences (Beck depression inventory) }{ }^{25} \\
\text { Higher scores in adherents (clinical interview) }\end{array}$ & Level of schooling ${ }^{13}$ \\
\hline $\begin{array}{l}\text { Higher expected I-year BMI loss }{ }^{23} \\
\text { Dietary habits such as lower } \\
\text { consumption of fresh fruits (modified } \\
\text { dietary history, with 3-day diary) }{ }^{13}\end{array}$ & & $\begin{array}{l}\text { Current smokers }{ }^{13} \\
\text { Triglyceride levels }^{10}\end{array}$ \\
\hline $\begin{array}{l}\text { Greater shape concern (eating } \\
\text { disorder examination questionnaire) }\end{array}$ & & $\mathrm{HbA}_{\mathrm{Ic}}$ values $^{10}$ \\
\hline $\begin{array}{l}\text { Lower self-esteem (Rosenberg's } \\
\text { self-esteem scale) }{ }^{25}\end{array}$ & & $\begin{array}{l}\text { Fatty cell mass }{ }^{10} \\
\text { Active cell mass }{ }^{10} \\
\text { Cholesterol values }^{10} \\
\text { Familiarity with the condition of obesity' } \\
\text { A diagnosis of binge-eating disorder } \\
\text { (assessed by interview method) }{ }^{25} \\
\text { Duration of binge eating } \\
\text { Frequency of previous therapy } \\
\text { Level of physical activity' } \\
\text { Dietary habits such as consumption of } \\
\text { vegetables, sweeteners, white meat, dairy } \\
\text { products, bread and cereals, alcoholic } \\
\text { beverages at mealtime (modified dietary } \\
\text { history, with 3-day diary) } \\
\text { Eating concerns (eating disorder } \\
\text { examination questionnaire) } \\
\text { Weight concerns (eating disorder } \\
\text { examination questionnaire) } \\
\text { Restraint (eating disorder examination } \\
\text { questionnaire })^{25}\end{array}$ \\
\hline
\end{tabular}

Abbreviation: BMI, body mass index.

Ernährung [Austrian Nutrition Society], Schweizerische Gesellschaft für Ernährungsforschung [Swiss Society for Nutrition Research], and Schweizerische Vereinigung für Ernährung [Swiss Association for Nutrition] nutrition recommendations for $2005-2006,{ }^{28}$ and a suitable nutrition plan was prepared. Compliance with the nutrition plan was verified, in part, through a nutrition journal. Following the development of nutrition recommendations, ${ }^{28}$ a goal was established for a daily energy deficit of 500-800 kcal. This deficit was primarily achieved by reducing nutritional fat intake and reducing the intake of food with a high glycemic index. Thus, a decrease in initial weight of approximately $500-800 \mathrm{~g}$ per week was possible. Based on the recommendations from the Deutsche Gesellschaft für Ernährung, ${ }^{28}$ well-balanced meals were low in fat and emphasized carbohydrates with a low glycemic index, high dietary fiber, and a moderate caloric deficit.

During nutrition therapy, patients learned to become aware of their dietary and nutritional needs, to enjoy food in quantities adjusted to their needs, and to flexibly control their diet. These topics were discussed in small, structured training courses. The methods used included lectures, controlled dialogue, discussion, group work, and theoretical and practical exercises (eg, cooking together in the kitchen). 


\section{Psychoeducation and behavioral therapy interventions}

Psychoeducation was conducted based on guidelines by psychotherapists. The most important steps included: (1) self-monitoring of eating and drinking habits (eg, using a nutrition journal as homework) to analyze triggers for increased energy consumption; (2) self-control of these triggers (eg, avoiding "grazing" or performing hobbies while eating); (3) training in flexible control of eating habits, in contrast to rigid behavioral control; and (4) strengthening achieved behavioral changes, including strategies to avoid regressing to unfavorable behavioral patterns to stabilize the new eating habits.

\section{Jacobson's progressive muscle relaxation (PMR)}

In addition to behavioral therapy methods, which aimed to improve coping behavior and improve stress tolerance, several surveys have shown that isolated stress-reduction methods have positive effects on metabolism regulation. ${ }^{29}$ Patients were regularly instructed on exercises for PMR according to Jacobson, a method that is easy to learn and can be maintained systematically even after the training program ends. Furthermore, patients were encouraged to improve their self-awareness and effectiveness by verbalizing their new experiences.

In the first 6 months, the interventions were conducted as group therapy, with 12 to 14 participants, twice per week for 2.5 hours $(2 \times 1 \mathrm{~h} /$ week movement therapy and training, $1 \times 1 \mathrm{~h} / 14$-day advice on diet and training, $1 \times 1 \mathrm{~h} / 14$-day psychoeducation and behavioral therapy interventions, $1 \times 30 \mathrm{~min} /$ week PMR). In the second 6 months, the interventions were conducted for 2.5 hours once per week. At the initial intake interview, the patient's medical history was taken and clinical examinations were performed, including a blood test and measurements of blood pressure, weight, waist and hip circumference; bioimpedance analysis; exercise electrocardiography; and psychological tests (standardized questionnaires) using personal digital assistants. (A detailed description of the program, the criteria for inclusion and exclusion, the evaluation procedure [approved by the ethics commission of the Charite - Universitätsmedizin Berlin; Application No EA 1/060/08] and its results are in Riedl et $\left.\mathrm{al}^{30}\right)$.

The data were collected between December 2007 and January 2011. Prior to this study, 301 patients had undergone an intake examination. Of these patients, 66 were not accepted into the program based on the exclusion criteria, or chose not to participate. A total of 219 patients were accepted for the study and were divided into 19 groups. Sixteen individuals were on the waiting list at the time of the study. The results reported in this paper were obtained from 164 patients in 14 groups who had completed the 12-month treatment.

\section{Materials and statistical procedures}

Data analysis was based on data collection during the initial intake interview, prior to the beginning of the program. The standardized questionnaires, comprising 327 items, were completed using personal digital assistants. Brief descriptions of the questionnaires are given in Table 2.

For the descriptive statistics of sociodemographic variables and data from the patients' medical histories, the somatic findings and the scale score frequencies and means (M), standard deviations (SD), and ranges (Min, Max) were calculated using the statistics software SPSS for Windows (v 18.0; IBM Corp, Armonk, NY).

The $t$-test for independent samples was employed to compare means. The equality of variances required for the $t$-test was established by Levene's test. Where the variances differed, the test statistic $t$ and the error probability $P$ were assessed based on the corrected degrees of freedom. The level of significance was set at $P<0.05$. A chi-square four-field test was used for nominally distributed variables.

Logistic regression was employed to determine the likelihood of the event "premature treatment discontinuation" dependent on the influencing parameters. To avoid overfitting, the original number of variables was reduced. The variables that had been shown to be significant in the $t$-test and chi-square test were entered into a correlation matrix to test for multicollinearity, which would lead to estimation problems. Variables with correlation values (Pearson's $r$ or Spearman's rho) $>0.08$ were eliminated.

The total scores of the tests were also either excluded or, when the scales were highly internally correlated, the results for the subscales were removed, and the total score was included in the model to avoid singularity (that is, perfect collinearity).

Two cases were identified as outliers with a Pearson's residual ( $\mathrm{z}$ residual) $>3$, and excluded from the analysis.

Patients reported their reasons for dropping out of the program to the team of therapists either in person or by telephone, email, or post to a member of the organization team. The reasons given were evaluated by qualitative content analysis (note that it was acceptable for patients to give multiple reasons). ${ }^{44,45}$ 
Table 2 Overview and descriptions of the measures employed

\begin{tabular}{ll}
\hline Parameter & Questionnaire \\
\hline Sociodemographic & SOZ - Questionnaire on social characteristics \\
parameters & (German-language measure used internally by the hospital) \\
Eating behavior & Binge-eating disorder (ICD-I0 F50.4 Overeating associated \\
& with other psychological disturbances or F50.8 Other eating \\
& disorders or F50.9 Eating disorder, unspecified; DSM IV \\
& 307.50 FK, appendix B). Polyphagia (ICD-I0 F 50.9 Eating \\
& disorder, unspecified or F50.8 Other eating disorders). \\
& Clinical initial intake interview by specialist in psychosomatic \\
& medicine
\end{tabular}

\section{Description}

I 7 items assessing age, sex, occupational status, family status, etc

\section{Criteria for binge-eating disorder (BED)}

On average, binge eating takes place twice weekly, and has done so for 6 months; while eating, there is a feeling of loss of control over the amount of food or type of food being consumed; eating noticeably faster than is considered normal; eating large quantities of food when not hungry; eating alone due to embarrassment of overeating; feelings of disgust, depression, or guilt after a binge; obvious distress concerning binge eating behavior; no recurring efforts to compensate for binge eating, such as purging or excessive exercise

\section{Criteria for polyphagia}

Continuous, excessive consumption of calories (no binge eating) for at least 6 months. Ignoring portion sizes and diet composition (high-calorie food) and eating small portions in the morning, consuming large portions at dinner and/or eating sweets (high-calorie snacks) and/or abnormally large intake of high caloric solids and/or night eating and/or eating in response to painful emotions

FEV - Fragebogen zum Essverhalten (questionnaire on eating behavior; original in German) ${ }^{31}$

EDI 2 - eating disorder inventory ${ }^{32}$

Perceptions

PSQ-20 - perceived stress questionnaire ${ }^{33}$

of stress

Subjective

complaints

GBB-24 - Giessener Beschwerdebogen ${ }^{34}$ (Giessen subjective complaints list)

Mental symptoms

ISR - ICD- I0-symptom-rating 35,36

Mood

BSF - Berliner Stimmungsfragebogen ${ }^{37}$ (Berlin mood questionnaire)

Depressiveness Depression scale of the PHQ - patient health questionnaire (German version: PHQ Gesundheitsfragebogen für Patienten ${ }^{38}$ )

Quality of life SF-8 - German version of the health survey ${ }^{39}$

Resources

SWOP - Fragebogen zu Selbstwirksamkeit, Optimismus und Pessimismus ${ }^{40}$ (assessment of beliefs in self-efficacy and optimism)

SOC-9 - German version of Antonovsky's sense of coherence scale (formerly the orientation to life scale $)^{41}$
66 items assessing eating behavior, grouped into three scales: "Cognitive control of eating behavior/controlled/restrained eating," "Disturbability of eating behavior" and "Perceived feelings of hunger"; Cronbach's alpha $=0.74$ to 0.87

64 items assessing the specific psychopathologies of patients with anorexia and bulimia nervosa and other psychogenic eating disorders. The brief version with eight scales was employed: "Drive for thinness," "Bulimia," "Body dissatisfaction,"

"Ineffectiveness," "Perfectionism," "Interpersonal distrust," "Interoceptive awareness," "Maturity fears";

Cronbach's alpha $=0.73$ to 0.93

20 items assessing current subjective perceptions of stress, summarized on four scales entitled "Worries," "Tension," "Joy," and "Demands"; Cronbach's alpha $=0.80$ to 0.86

24 items assessing various complexes of complaints subdivided into four scales: "Exhaustion," "Upper abdominal discomfort," "Aching joints and muscles," "Subjective heart complaints" and the total scale score "Pressure of subjective complaints"; Cronbach's alpha $=0.82$ to 0.94

29 items assessing mental symptoms modeled on the syndromal approach of the ICD-I0, listed on five scales: "Depressive syndrome," "Anxiety syndrome," "Obsessive syndrome," "Somatoform syndrome," "Eating disorder syndrome"; Cronbach's alpha $=0.78$ to 0.86

30 items on six scales assessing "Tiredness," "Apathy," "Anxious depressiveness," "Anger," "Commitment," "Good mood" 15 items assessing depression; Cronbach's alpha $=0.85$ to 0.90

Eight items assessing health-related quality of life, using the two total scores for "mental health" and "physical health"; Cronbach's alpha (for long form) $=0.57$ to 0.94

Nine items assessing self-efficacy, optimism and pessimism on three independent scales; Cronbach's alpha $=0.54$ to 0.86

Nine items assessing the sense of coherence; Cronbach's alpha (for total score) $=0.87$ 
Table 2 (Continued)

\begin{tabular}{lll}
\hline Parameter & Questionnaire & Description \\
\hline & PAS - perceived available support, subscale of the & Eight items assessing perceived emotional and perceived \\
& Berlin social support scale 42 & instrumental social support; Cronbach's alpha = 0.83 \\
Coping strategies & German version of the Brief-COPE ${ }^{43}$ & 28 items assessing coping behavior in past difficult or unpleasant \\
& & situations, subdivided into four scales: "support coping," \\
& "positive reframing," "avoidant coping” and "active coping”; & Cronbach's alpha $=0.70$ to $0.8 \mathrm{I}$ \\
\hline
\end{tabular}

\section{Results}

\section{Attrition rate, timing, and reasons for dropping out}

At the time of data analysis, 71 of the 164 patients accepted for the study (138 women, 26 men; age: $M=45.46$ years, $\mathrm{SD}=11.46$, range: $16-72$ years) had dropped out of the program.

The average duration of treatment for the dropouts was 23.15 weeks (range $=0-50$ weeks, SD $=14.31$ ). A total of $32.4 \%(n=23)$ of the patients dropped out of treatment during the first 3 months, $23.9 \%(n=17)$ dropped out between the third and sixth months, $26.8 \%(n=19)$ dropped out between the sixth and ninth months, and $16.9 \%(n=12)$ dropped out in the 3 months before the end of the program. The reasons given by the patients for dropping out are shown in Table 3.

Table 3 Reasons for discontinuing treatment, from patients' perspectives

\begin{tabular}{|c|c|c|}
\hline n & Reason for dropping out & Examples \\
\hline 22 & Changes in health & $\begin{array}{l}\text { - Development/deterioration of } \\
\text { physical and mental diseases } \\
\text { - Inpatient or outpatient } \\
\text { treatment needed }\end{array}$ \\
\hline 17 & Family/work changes & $\begin{array}{l}\text { - Care of relatives, or illness or } \\
\text { death of relatives } \\
\text { - Change in work situation/ } \\
\text { shift work }\end{array}$ \\
\hline II & Takes too much time & \\
\hline 9 & $\begin{array}{l}\text { Dissatisfaction with treatment } \\
\text { modules/individual therapists/ } \\
\text { other group members }\end{array}$ & \\
\hline 6 & Too expensive & $\begin{array}{l}\text { - Financial difficulties } \\
\text { - Unwilling to pay the } € 25 \\
\text { monthly contribution } \\
\text { expected from insurance } \\
\text { subscribers }\end{array}$ \\
\hline 17 & No reason given by patient & $\begin{array}{l}\text { In } 14 \text { cases, the therapists } \\
\text { noted a lack of compliance, } \\
\text { lack of or low treatment } \\
\text { motivation, and externalization } \\
\text { of responsibility }\end{array}$ \\
\hline
\end{tabular}

\section{Analysis of sociodemographic, somatic, and psychological factors}

Significant differences between program adherents and dropouts were found by age (adherents: $n=93, M=47.40$, $\mathrm{SD}=11.01$; dropouts: $\mathrm{n}=71, \mathrm{M}=42.92, \mathrm{SD}=11.62$; $t=2.52$, degrees of freedom [df] $=162, P=0.013^{*}, \mathrm{~d}=0.40$ ), family status (adherents: partner relationship/no partner relationship: $\mathrm{n}=57 / 32$; dropouts: partner relationship/no partner relationship: $\mathrm{n}=32 / 38 ; \chi^{2}=5.34, \mathrm{df}=1, P=0.021^{*}$, $\mathrm{d}=0.37$ ) and work situation (adherents: gainfully employed/ not gainfully employed: $n=65 / 23$; dropouts: gainfully employed/not gainfully employed: $\mathrm{n}=40 / 28 ; \chi^{2}=3.94, \mathrm{df}=1$, $P=0.047^{*}, \mathrm{~d}=0.32$ ). No significant difference was found by sex (adherents: $\mathrm{m} / \mathrm{f}: \mathrm{n}=16 / 77$; dropouts: $\mathrm{m} / \mathrm{f}: \mathrm{n}=10 / 61$; $\left.\chi^{2}=0.29, \mathrm{df}=1, P=0.059\right)$.

As shown in Table 4, there were no significant differences between the adherents and the dropouts regarding somatic variables and parameters for metabolism.

Of the 162 patients examined, $1.23 \%(\mathrm{n}=2)$ of the patients were not seen by a specialist in psychosomatic medicine before starting the program, $13.58 \%(\mathrm{n}=22)$ were found to have a binge-eating disorder, and $77.78 \%(\mathrm{n}=126)$ of the patients had polyphagia.

Overall, $10.75 \%(\mathrm{n}=10)$ of the 93 treatment adherents and $17.39 \%(n=12)$ of the 69 dropouts were diagnosed with a binge-eating disorder. A chi-square four-field test showed that there was no significant difference between these two groups $\left(\chi^{2}=1.49, \mathrm{df}=1, P=0.223\right)$, which suggests that the variables of treatment dropout and binge-eating disorder are independent of each other.

The same finding applies to polyphagia: $79.57 \%(\mathrm{n}=74)$ of the program adherents $(n=93)$ and $75.36 \%(n=52)$ of the 69 dropouts had polyphagia. Again, the chi-square showed that there was no significant difference $\left(\chi^{2}=406, \mathrm{df}=1\right.$, $P=0.524)$.

All other psychological variables investigated by means of the $t$-test are shown in Table 5 .

The dropouts differed significantly from the adherents on a large number of psychological variables (taking 
Table 4 No significant results for the t-tests of independent samples conducted to determine differences in the means for the somatic variables for adherents and dropouts

\begin{tabular}{|c|c|c|c|c|c|c|c|}
\hline \multirow{2}{*}{$\begin{array}{l}\text { Measures of dispersion } \\
\text { Variables }\end{array}$} & \multicolumn{2}{|c|}{ Adherents $(n=91-93)$} & \multicolumn{2}{|c|}{ Dropouts $(n=65-7 I)$} & \multicolumn{3}{|l|}{$t$-test } \\
\hline & $M$ & SD & $M$ & SD & $t$ & df & $P$ \\
\hline Weight in $\mathrm{kg}^{\mathrm{a}}$ & 112.23 & 25.34 & 113.48 & 21.19 & -0.34 & 162 & 0.737 \\
\hline $\mathrm{BMI}$ in $\mathrm{kg} / \mathrm{m}^{2}$ & 39.59 & 6.52 & 39.53 & 6.70 & 0.07 & 162 & 0.948 \\
\hline Waist circumference in $\mathrm{cm}$ & 120.07 & 16.54 & 118.94 & 15.14 & 0.44 & 156 & 0.663 \\
\hline Hip circumference in cm & 131.54 & 16.02 & 130.14 & 13.82 & 0.58 & 156 & 0.565 \\
\hline Systolic RR (mmHg) & 130.48 & 14.87 & 127.62 & 16.61 & 1.15 & 158 & 0.254 \\
\hline Diastolic RR (mmHg) & 84.27 & 11.14 & 84.00 & 12.13 & 0.15 & 158 & 0.882 \\
\hline BIA: fatty mass in $\mathrm{kg}$ & 49.61 & 14.24 & 49.86 & 13.30 & -0.11 & 152 & 0.911 \\
\hline BIA: muscle mass in $\mathrm{kg}$ & 31.47 & 8.07 & 31.70 & 10.02 & -0.18 & 152 & 0.856 \\
\hline BIA: body water in $\mathrm{kg}$ & 45.68 & $1 \mathrm{I} .57$ & 45.52 & 9.27 & 0.09 & 152 & 0.930 \\
\hline Fasting glucose (mg/dL) & 101.11 & 31.05 & 98.49 & 25.56 & 0.56 & 157 & 0.573 \\
\hline $\mathrm{HbA}_{\mathrm{Ic}}(\%)$ & 5.73 & 0.94 & 5.75 & 0.96 & -0.16 & 154 & 0.874 \\
\hline HDL (mg/dL) & 52.46 & 15.92 & 52.32 & 12.99 & 0.06 & 157 & 0.952 \\
\hline LDL (mg/dL) & 124.96 & 27.99 & 118.11 & 27.68 & 1.53 & 157 & 0.129 \\
\hline Triglycerides $(\mathrm{mg} / \mathrm{dL})^{\mathrm{c}, \mathrm{d}}$ & 129.67 & 64.06 & 161.83 & 123.13 & -1.93 & 88.55 & 0.057 \\
\hline ASAT $(U / /)^{e}$ & 27.98 & 10.62 & 28.25 & 9.18 & -0.16 & 155 & 0.870 \\
\hline ALAT (U/I) & 31.22 & 18.37 & 32.42 & 18.83 & -0.40 & 155 & 0.691 \\
\hline GGT (U/I) & 32.04 & 27.96 & 32.17 & 43.83 & -0.02 & 155 & 0.983 \\
\hline Cholesterol & 202.13 & 36.03 & 197.63 & 35.31 & 0.79 & 158 & 0.433 \\
\hline Uric acid & 5.26 & 1.27 & 5.58 & 1.22 & -1.56 & 155 & 0.120 \\
\hline
\end{tabular}

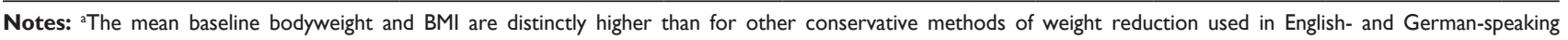

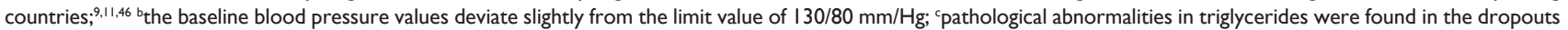
$(>150 \mathrm{mg} / \mathrm{dL}),{ }^{47}$ but not in the program adherents $(<150 \mathrm{mg} / \mathrm{dL})$; ${ }^{d}$ one case was excluded from the analysis of the triglycerides because it was an extreme outlier $(2323 \mathrm{mg} / \mathrm{dL})$; ${ }^{e}$ the transaminases used to diagnose nonalcoholic steatohepatitis were within the reference range in both groups (ALAT < $34 \mathrm{U} / \mathrm{l}$, ASAT $<35 \mathrm{U} / \mathrm{l}$, GGT $\left.<38 \mathrm{U} / \mathrm{I}\right)$.

Abbreviations: ALAT, alanine aminotransferase; ASAT, aspartate aminotransferase; BIA, bioelectrical impedance analysis; BMI, body mass index; GGT, gamma-glutamyl transpeptidase; HDL, high-density lipoprotein; LDL, low-density lipoprotein; RR, respiratory rate.

into account the accumulation of alpha errors and the corresponding corrections). In particular, we found significant differences regarding perceived stress (Perceived Stress Questionnaire [PSQ]), subjective complaints (Giessener Beschwerdebogen [GBB-24]), mood (BSF), depression (depression scale of the Patient Health Questionnaire - German version: Gesundheitsfragebogen für Patienten [PHQ]; depression scale of the ICD-10-symptom-rating [ISR]), and mental quality of life (brief German version of the health survey [SF-8]). The dropouts had less favorable scores than the adherents before the start of treatment.

The predictive value of the parameters investigated was determined with the aid of logistic regression analysis.

Following an examination of the requirements of the statistical procedures and considerations of content (ie, the detection of suspected suppressor effects for expectations of self-efficacy and coping strategies in view of the importance assigned to these variables for treatment adherence), the following variables were entered into the regression model: age, family status (reference category: no partner relationship), work (reference category: no gainful employment), anxiety syndrome (ISR), somatoform syndrome (ISR), subjective complaints (GBB), perceived stress (PSQ), feeling of anger
(BSF), anxious-depressed mood (BSF), tiredness (BSF), apathy (BSF), mental health (SF-8), sense of coherence (German version of Antonovsky's sense of coherence scale, formerly the orientation of life scale [SOC-9]), expectation of selfefficacy (SWOP), pessimism (SWOP), depression (PHQ), ineffectiveness (Eating Disorder Inventory [EDI 2]), avoidant coping (Brief-COPE), support coping (Brief-COPE), positive reframing (Brief-COPE), and active coping (Brief-COPE).

The dataset was reduced from 162 to 136 cases $(16 \%$ reduction in size) due to missing data. For the calculation of the model, all selected variables were entered simultaneously.

As is shown in Table 6, the likelihood of unemployed patients dropping out of the program was 30.58 times greater than for patients who were working. Moreover, the likelihood of dropping out increased by odds ratio $=23.51$ per scale interval of the self-efficacy expectation on the SWOP, increased 17.29-fold if patients had a change of one unit on the "tiredness" scale of the BSF, and increased 5.20-fold with each unit of the pessimism scale in the SWOP questionnaire. The coping strategy of positive reframing, as assessed by the Brief-COPE measure, proved unfavorable for treatment adherence; the likelihood of dropping out increased 1.43-fold if the score on this scale changed by one scale unit. 
Table 5 To determine differences in the means for the psychological variables for the adherents and dropouts, $t$-tests for independent samples (with correction of the alpha error as described by Bonferroni-Holm) and effect sizes (d) calculated by Cohen's method were conducted

\begin{tabular}{|c|c|c|c|c|c|c|c|c|}
\hline \multirow[t]{2}{*}{$\begin{array}{l}\text { Measures of dispersion } \\
\text { Variables }\end{array}$} & \multicolumn{2}{|c|}{$\begin{array}{l}\text { Adherents } \\
(n=86-90)\end{array}$} & \multicolumn{2}{|c|}{$\begin{array}{l}\text { Dropouts } \\
(n=63-69)\end{array}$} & \multicolumn{3}{|l|}{$t$-test } & \multirow[t]{2}{*}{ d } \\
\hline & $\bar{M}$ & SD & $\bar{M}$ & SD & $t$ & df & $P$ & \\
\hline \multicolumn{9}{|l|}{ FEV } \\
\hline Cog control eating behavior & 9.41 & 4.31 & 9.44 & 4.78 & -0.50 & 147 & 0.960 & \\
\hline Disturbability of eating behavior & 8.79 & 3.61 & 8.76 & 3.73 & 0.05 & 147 & 0.962 & \\
\hline Perceived feelings of hunger & 6.48 & 3.75 & 5.98 & 3.90 & 0.78 & 147 & 0.438 & \\
\hline \multicolumn{9}{|l|}{ EDI } \\
\hline Total score & 187.94 & 6.55 & 205.10 & 45.75 & -2.67 & 155 & $0.008^{* *}$ & -0.53 \\
\hline Drive for thinness & 25.10 & 7.01 & 26.61 & 6.83 & $-1.4 \mid$ & 155 & 0.162 & \\
\hline Bulimia & 15.29 & 7.75 & 16.46 & 7.59 & -1.00 & 155 & 0.318 & \\
\hline Body dissatisfaction & 44.92 & 8.50 & 45.85 & 7.87 & -0.74 & 155 & 0.462 & \\
\hline Ineffectiveness & 23.26 & 8.50 & 27.96 & 10.82 & -2.94 & 121.58 & $0.004^{* *}$ & -0.48 \\
\hline Perfectionism & 17.04 & 5.83 & 17.90 & 6.26 & -0.88 & 155 & 0.382 & \\
\hline Interpersonal distrust & 19.06 & 6.11 & 21.49 & 6.42 & -2.42 & 155 & $0.017^{*}$ & -0.39 \\
\hline Interoceptive awareness & 22.23 & 7.38 & 25.84 & 9.49 & -2.58 & 120.64 & $0.01 I^{*}$ & -0.42 \\
\hline Maturity fears & 21.04 & 4.78 & 23.00 & 6.24 & -2.14 & 119.44 & $0.034^{*}$ & -0.35 \\
\hline \multicolumn{9}{|l|}{ PSQ } \\
\hline Total score & 0.39 & 0.21 & 0.51 & 0.25 & -3.49 & 156 & $0.00 \mathrm{I} * *$ & -0.52 \\
\hline General demands & 0.39 & 0.23 & 0.46 & 0.26 & -1.83 & 156 & 0.069 & \\
\hline Tension & 0.42 & 0.26 & 0.57 & 0.26 & -3.61 & 156 & $<0.00 I^{* * *}$ & -0.58 \\
\hline Worries & 0.33 & 0.24 & 0.45 & 0.30 & -2.82 & 126.27 & $0.004^{* *}$ & -0.44 \\
\hline $\begin{array}{l}\text { Joy } \\
\text { GBB }\end{array}$ & 0.60 & 0.26 & 0.43 & 0.28 & 3.86 & 156 & $0.003^{* *}$ & 0.63 \\
\hline Total score & 23.09 & 14.86 & 34.97 & 20.70 & -4.04 & 118.21 & $<0.00 I^{* * *}$ & -0.66 \\
\hline Exhaustion & 6.97 & 5.63 & 10.96 & 7.27 & -3.78 & 124.76 & $<0.00 I^{* * *}$ & -0.61 \\
\hline Aching joints and muscles & 9.78 & 5.35 & 12.06 & 6.16 & -2.49 & 134.63 & $0.014^{*}$ & -0.40 \\
\hline Abdomen & 3.33 & 3.26 & 6.16 & 4.82 & -4.19 & 113.29 & $<0.001 * * *$ & -0.69 \\
\hline Heart & 3.01 & 3.57 & 5.80 & 5.38 & -3.72 & 111.82 & $<0.00 I^{* * *}$ & -0.61 \\
\hline \multicolumn{9}{|l|}{ ISR } \\
\hline Total score & 0.72 & 0.53 & 1.09 & 0.74 & -3.51 & 117.53 & $0.00 \mathrm{I} * *$ & -0.57 \\
\hline Depressive syndrome & 0.87 & 0.96 & 1.53 & 1.17 & -3.82 & 129.37 & $<0.001 * * *$ & -0.62 \\
\hline Anxiety syndrome & 0.68 & 0.73 & 1.12 & 1.10 & -2.92 & 111.79 & $0.004^{* *}$ & -0.47 \\
\hline Obsessive syndrome & 0.52 & 0.73 & 0.80 & 0.95 & -2.04 & $123.9 \mid$ & $0.044^{*}$ & -0.33 \\
\hline Somatoform syndrome & 0.37 & 0.65 & 0.79 & 0.99 & -3.07 & 110.97 & $0.008^{* *}$ & -0.50 \\
\hline Eating disorder syndrome & 1.59 & 0.92 & 1.67 & 0.93 & -0.59 & 157 & 0.559 & \\
\hline \multicolumn{9}{|l|}{ BSF } \\
\hline Good mood & 1.83 & 1.05 & 1.32 & 1.11 & 2.93 & 156 & $0.004^{* *}$ & 0.47 \\
\hline Commitment & 2.36 & 0.83 & 2.12 & 0.73 & 1.96 & 156 & 0.052 & \\
\hline Feeling of anger & 0.51 & 0.59 & 0.90 & 0.94 & -3.01 & 105.55 & $0.003^{* *}$ & -0.50 \\
\hline Anxious-depressed mood & 0.91 & 0.84 & 1.51 & 1.16 & -3.59 & 117.01 & $<0.00 \mathrm{I} * * *$ & -0.59 \\
\hline Tiredness & 1.20 & 0.97 & 1.89 & 1.14 & -4.12 & 156 & $<0.00 I^{* * *}$ & -0.65 \\
\hline Apathy & 0.37 & 0.56 & 0.77 & 0.86 & -3.39 & 108.17 & $0.00 I^{* *}$ & -0.55 \\
\hline PHQ-depression & 6.14 & 5.50 & 9.80 & 6.39 & -3.79 & 134.16 & $<0.00 I^{* * *}$ & -0.61 \\
\hline \multicolumn{9}{|l|}{ SF-8 } \\
\hline Total mental score & 49.50 & 10.79 & 42.25 & 10.79 & 3.59 & 124.72 & $<0.00 I^{* * *}$ & 0.67 \\
\hline Total physical score & 41.47 & 9.59 & 37.91 & 10.75 & 2.19 & 154 & $0.030 *$ & 0.35 \\
\hline \multicolumn{9}{|l|}{ PAS } \\
\hline Emotional support & 13.84 & 2.46 & 13.00 & 3.27 & 1.77 & 120.77 & 0.080 & \\
\hline Instrumental support & 13.64 & 2.72 & 12.75 & 3.40 & 1.76 & 126.08 & $0.08 I$ & \\
\hline soc & 5.15 & 1.06 & 4.46 & 1.26 & 3.77 & 155 & $<0.00 I^{* * *}$ & 0.59 \\
\hline \multicolumn{9}{|l|}{ SWOP } \\
\hline Self-efficacy & 2.86 & 0.61 & 2.79 & 0.71 & 0.66 & 152 & 0.510 & \\
\hline Optimism & 3.03 & 0.77 & 2.74 & 0.94 & 2.08 & $|28.3|$ & $0.040 *$ & 0.34 \\
\hline Pessimism & 1.98 & 0.71 & 2.39 & 0.71 & -3.55 & 152 & $0.00 I^{* *}$ & -0.58 \\
\hline
\end{tabular}


Table 5 (Continued)

\begin{tabular}{|c|c|c|c|c|c|c|c|c|}
\hline \multirow[t]{2}{*}{$\begin{array}{l}\text { Measures of dispersion } \\
\text { Variables }\end{array}$} & \multicolumn{2}{|c|}{$\begin{array}{l}\text { Adherents } \\
(\mathrm{n}=86-90)\end{array}$} & \multicolumn{2}{|c|}{$\begin{array}{l}\text { Dropouts } \\
(n=63-69)\end{array}$} & \multicolumn{3}{|l|}{$t$-test } & \multirow[t]{2}{*}{ d } \\
\hline & $\mathbf{M}$ & SD & $\mathbf{M}$ & SD & $t$ & df & $P$ & \\
\hline \multicolumn{9}{|l|}{ COPE } \\
\hline Avoidant coping & 11.73 & 2.98 & 12.96 & 3.64 & -2.32 & 154 & $0.022^{*}$ & -0.37 \\
\hline Support coping & 12.33 & 3.13 & 11.93 & 3.41 & 0.77 & 154 & 0.444 & \\
\hline Positive reframing & 11.89 & 3.42 & 12.24 & 2.79 & -0.68 & 154 & 0.495 & \\
\hline Active coping & 11.22 & 2.62 & 11.29 & 2.41 & -0.19 & 154 & 0.848 & \\
\hline
\end{tabular}

Notes: $* \mathrm{P}<0.05 ; * * \mathrm{P}<0.01$; ***P $<0.001$. Correction of the alpha error for each psychometric test as described by Bonferroni-Holm (values marked in bold are significant after correction).

Abbreviations: FEV, Fragebogen zum Essverhalten (Questionnaire on Eating Behavior; original in German); ${ }^{31}$ EDI, Eating Disorder Inventory; ${ }^{32}$ PSQ, Perceived Stress Questionnaire; ${ }^{33} \mathrm{GBB}$, Giessener Beschwerdebogen ${ }^{34}$ (Giessen Subjective Complaints List); ISR, ICD-I0-Symptom-Rating; ${ }^{35,36}$ BSF, Berliner Stimmungsfragebogen ${ }^{37}$ (Berlin Mood Questionnaire); PHQ, Patient Health Questionnaire; SF-8, German version of the Health Survey; ${ }^{39}$ PAS, Perceived Available Support, subscale of the Berlin Social Support Scale; ${ }^{42}$ SOC, Sense of Coherence Scale (formerly the Orientation to Life Scale); SWOP, Fragebogen zu Selbstwirksamkeit, Optimismus und Pessimismus ${ }^{40}$ (Assessment of Beliefs in Self-Efficacy and Optimism); COPE, German version of the Brief-COPE. ${ }^{43}$

In contrast, the coping strategy of support coping was found to be favorable. The likelihood of dropping out decreased 0.67 -fold with a change of one scale unit. The likelihood of dropping out also decreased 0.88 -fold with each year of age.

\section{Discussion}

The attrition rate of $43.3 \%$ in our study lies within the medium range of rates reported by comparable conservative weight-reduction programs, which report attrition rates of up to $77.3 \% .^{13,22}$ The results of the current study show the highest attrition rate within the first 3 months, which is similar to results reported by Inelmen et al (1-year multimodal program; $\mathrm{N}=383$, age: range $=15-82) \cdot{ }^{13}$ However, the program ended with a comparably large number of dropouts between months 6 and 9. Weight loss frequently slows or stagnates during this period, which can lead participants to drop out of the program despite previous warnings about this phenomenon. As well as this, the frequency of treatment units was halved after 6 months to promote autonomy and disengagement. This reduction may lead patients to consider abandoning the program.

The two primary reasons for dropping out reported by our patients were (1) changes in health status that required them to be admitted to the hospital or undergo outpatient treatment and (2) changes in their family or work situations.

In the study by Andersson and Rössner, the male participants who dropped out $(\mathrm{n}=19$, attrition rate $=22 \%)$ during the first year of the 2-year multimodal program (nutrition and behavioral therapy interventions, $\mathrm{N}=86$, age: $\mathrm{M}=43$, BMI: $\mathrm{M}=37.7 \mathrm{~kg} / \mathrm{m}^{2}$ ) reported personal problems $(n=5)$ such as caring for relatives or alcohol problems; no longer wishing to participate $(n=5)$; "illness" $(n=2)$ or "moving" $(\mathrm{n}=2) \cdot{ }^{12}$ In five cases, no reasons for dropping out could be identified. ${ }^{12}$

In Nauta et al's study (15 weeks cognitive behavioral or behavioral therapy interventions; $\mathrm{N}=74$, age: $\mathrm{M}=38.6$, $\mathrm{BMI}$ : $\left.\mathrm{M}=33 \mathrm{~kg} / \mathrm{m}^{2}\right){ }^{25}$ of the ten dropouts (attrition rate $=13.5 \%$ ), four reported that they stopped participating after losing an unsatisfactory amount of weight, two stated that they stopped

Table 6 Predictors of cessation of the weight loss program according to multiple logistic regression analysis

\begin{tabular}{|c|c|c|c|c|c|c|}
\hline Explanatory variable & $\begin{array}{l}\text { Regression } \\
\text { coefficient }\end{array}$ & Standard-error & $P$-value & $\begin{array}{l}\text { Difference for } \\
\text { odds-ratio }\end{array}$ & Odds ratio ${ }^{a}$ & $\begin{array}{l}95 \% \text { confidence } \\
\text { interval }\end{array}$ \\
\hline Not working & 3.42 & 0.91 & $<0.001$ & Not working/working & 30.58 & $5.10-183.19$ \\
\hline Self-efficacy expectation & 3.16 & 0.94 & 0.001 & 1 & 23.51 & $3.70-149.28$ \\
\hline Tiredness & 2.85 & 0.79 & $<0.001$ & 1 & 17.29 & $3.66-81.61$ \\
\hline Pessimism & 1.65 & 0.57 & 0.004 & 1 & 5.20 & $1.71-15.87$ \\
\hline Positive reframing & 0.36 & 0.11 & 0.001 & 1 & 1.43 & $1.16-1.77$ \\
\hline Age & -0.13 & 0.03 & $<0.001$ & I & 0.88 & $0.82-0.94$ \\
\hline Support coping & -0.39 & 0.13 & 0.002 & I & 0.67 & $0.53-0.86$ \\
\hline
\end{tabular}

Notes: Omnibus test of model coefficients: $\chi^{2}=84.16, \mathrm{df}=21, P<0.001$. Nagelkerke's $\mathrm{R}^{2}=0.62$. Analysis of the classification results: groups were not equally distributed;

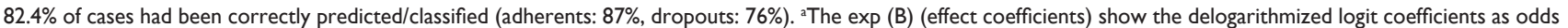
ratios; I = no change and thus no influence of the predictor, $<\mathrm{I}=$ increase in the exogenous variable reduces the probability of the occurrence of $y=I$ as opposed to $y=0$ (marked in italics), $>I=$ increase in the exogenous variable increases the probability of the occurrence of $y=I$ as opposed to $y=0$ (marked in bold type). 
due to time spent travelling, and four reported that current stressful life events were their reasons for discontinuation.

Twelve of the 35 subjects who dropped out of the 1-year study by Scholz et al ${ }^{11}(\mathrm{~N}=119$, age: range $=18-70$, $\mathrm{BMI} \geq 25 \mathrm{~kg} / \mathrm{m}^{2}$, attrition rate $=30.25 \%$ ) provided other personal reasons for doing so, including three who moved to a new job and two who stated family reasons. One complained that the program was too expensive and twelve subjects reported having lost interest in the study. Five subjects failed to respond when asked why they had dropped out of the program.

Grossi et al determined the reasons for dropping out among 766 subjects out of 940 study participants (attrition rate $=81.5 \%$, including therapy interventions such as dieting, cognitive behavioral therapy, drugs, and bariatric surgery at different Italian centers; age: $\mathrm{M}=49, \mathrm{BMI}: \mathrm{M}=38.6 \mathrm{~kg}$ / $\mathrm{m}^{2}$ ) by using structured phone interviews 3-4 years after the cessation of treatment. ${ }^{48}$ Almost half $(45 \%)$ of the primary causes of attrition ${ }^{48}$ involved practical difficulties (such as family problems, problems at work, or distance problems), followed by unsatisfactory results (14\%), low motivation $(12 \%)$, lack of confidence in the ability to lose additional weight without professional help (9\%), dissatisfaction with the achieved results (7\%), and disagreement with the treatment plan $(5 \%)$.

The variety and content of the reasons provided by our subjects are comparable with the findings of other studies. ${ }^{11,12,25,48}$

None of the somatic parameters for the dropouts and adherents investigated in the current study showed significant differences between the two groups. Dropouts and adherents showed similar eating habits and similar behaviors associated with eating disorders (these results reflect those reported by Nauta et $\mathrm{al}^{25}$ and Inelmen et $\mathrm{al}^{13}$ ). Previous studies revealed that obese patients with binge-eating disorder suffered from depression more often than obese patients without bingeeating disorder or with subclinical binge-eating disorder. ${ }^{49-51}$ Similar results were found for trait anxiety ${ }^{50}$ and external and emotional eating. ${ }^{50}$ These symptoms were similar in severity to those of patients with bulimia. ${ }^{52}$ The results also showed that patients dropped out of treatment more frequently due to these problems.

In the current study, a subanalysis showed that binge eaters had significantly higher scores for depressiveness (PHQ) and higher scores on the "depression syndrome" scale of the ISR ( $P<0.001$ and $P<0.01$, respectively).

Marked differences were found between dropouts and adherents for "depressiveness" (PHQ and ISR), "anxiety" (ISR), "somatization" (ISR), and mental health as a dimension of "quality of life" (SF-8). The dropouts also had less favorable scores than the adherents on five of the six mood dimensions of the BSF and on "perceived stress" (PHQ) prior to the start of the treatment. The mood variable "tiredness," at T0, proved to be a clear predictor of treatment discontinuation. If an obese patient feels weak, tired, listless, weary, or exhausted before the start of treatment, this is a warning signal that he or she is more likely to drop out of the treatment. In line with our expectations, the feeling that things never go as expected or that they never develop as one wishes - which is covered by the variable "pessimism" - also increases the likelihood of treatment dropout.

In the present study, the resource "expectation of selfefficacy" proved to be a strong predictor of premature discontinuation of treatment when the effects of the other variables were controlled for. This finding may appear to be counter-intuitive. A range of studies have shown that a high expectation of self-efficacy (ie, the subjective certainty that one will be able to perform difficult actions due to one's own skills and abilities) counteracts maladaptive modes of dealing with illness and promotes active coping with illness, ${ }^{53}$ so it could therefore be assumed that a high score would be indicative of adherence to the weight-reduction program. However, it appears that patients with a high expectation of self-efficacy believe that they can lose weight without professional help and decide to drop out of the program as a result. Thus, analysis of the current study's results found that the coping strategy "positive reframing" (positive reframing, humor and acceptance, Brief-COPE) also increased the likelihood of participants dropping out. It appears that this positively connoted intrapsychic mode of processing is suggestive of an adaptive function, but it is also associated with distortions of reality and massive self-deception. ${ }^{54}$ Self-deception is similar to a high expectation of self-efficacy in that it appears to be associated with the idea that it is possible to continue losing weight without professional help. Against the background of these findings, a critical evaluation of patients' reasons for dropping out of treatment is needed.

The reasons for dropping out that were most frequently reported by the current study's patients included changes in health status and changes in family and work situations. However, approximately the same number of patients did not offer clear reasons for dropping out. The third and fourth most frequently cited reasons included time problems and dissatisfaction with treatment modules, individual therapists, and other group members. A small number of patients complained about the financial cost of $€ 25$ per month. These reasons have also been found in other studies. ${ }^{11,12,25,48}$ 
It appears that key factors in the discontinuation of therapy by obese people include distortions of reality and massive self-deception, which lead to the externalization of responsibility, low motivation for therapy, and lack of compliance. These conscious and unconscious processes, which are related to self-esteem, may result in patients failing to provide a reason for dropping out or result in their providing socially acceptable reasons (eg, "illness" or "therapy takes too much time"). This last reason contrasts with our finding that "not working" (which could suggest that an unemployed person has more time to participate) is the most important predictor for dropping out. These findings are extremely interesting and require further investigation with complex, qualitative studies specifically designed to look into these factors.

Participants who demonstrated the coping strategy "support coping" (use of emotional and instrumental support; Brief-COPE) were more likely to accept help from third parties and thus complete the program.

In contrast with previous findings, the current study found that participants who worked were more likely to adhere to the treatment. Inelmen et $\mathrm{l}^{13}$ found that non-working patients had more free time, but in the current study it is suggested that the patients who were working were better able to deal with the structured procedures and to keep appointments because they were accustomed to these practices in their working lives. This difference may also be cultural (Italy vs Germany), although there is no evidence for this.

No previous research could be found that investigated possible differences in attrition between Europe and the USA. Honas et $\mathrm{al}^{27}$ investigated differences between white and African American populations in the USA with no difference found in their likelihood of dropping out (after logistic regression analysis).

As reported by Inelmen et al, ${ }^{13}$ Scholz et al, ${ }^{11}$ and Weisbrod, ${ }^{10}$ sex had no effect on the dropout rate. This finding seems to be consistent across studies.

Those who dropped out of the current study were on average significantly younger than the treatment adherents. This finding is consistent with the findings of Andersson and Rossner ${ }^{12}$ and Dalle Grave et al. ${ }^{23}$ Older people can be assumed to have experienced a larger number of frustrating experiences with diet and treatments than young people, which may make it more likely for older people to adhere to a supervised treatment regime.

Overall, it seems clear that it is possible to identify patients who are likely to drop out of weight loss programs based on sociodemographic and psychometric variables that can be measured prior to the start of treatment. Groups that are more homogeneous can be established in which certain issues can be managed with the aid of psychoeducation and behavioral therapy in a focused and differentiated manner. For example, critical modes of addressing high expectations of self-efficacy can be promoted by activating memories of previous experiences to verify reality (comparing imagination/ expectations with reality). Dysfunctional cognitive schemata, such as a pessimistic attitude, can be detected and cognitively restructured with the help of the other participants and their perspectives on reality.

It appears that participants need to concentrate on ways to reprogram any maladaptive coping mechanisms ("positive reframing") more than has been emphasized in the past. These mechanisms must be replaced by more adaptive modes of coping by emphasizing evidence of the mortality and both physical and mental morbidity that are associated with obesity.

Prior unsuccessful experiences of treatment can be discussed and compared in the group to allow the younger participants to benefit from the older participants who have more experience with treatment. The reasons and conditions for increased tiredness must be explored, and ways of reducing it must be developed in conjunction with the patients. The subject of work must be included in the behavioral therapy module of the program. It would be beneficial to include a social worker in a consultant role at the beginning of the treatment program. These necessary adaptations to the treatment manual are currently being conducted at the authors' hospital.

\section{Limitations of the study}

The current study was a retrospective analysis of the potential psychological and sociodemographic variables predicting attrition. Data collection was based on a naturalistic design to evaluate the quality of a treatment program in a clinical setting. This study was not designed as a clinical trial study under controlled experimental conditions with randomized samples, so it is not possible to draw conclusions about the efficiency of single therapy modules. Furthermore, the sample size could lead to certain limitations in data interpretation.

There is no evidence that the results of this study can be generalized to other western countries. Compliance in Germany may be different from other countries. In addition, the nature of self-reports should be considered critically. A possible disadvantage of self-reports is that various biases, such as social desirability bias, may affect the results. 


\section{Acknowledgments}

We would like to thank Ms Lilly Roßkopf for her help in preparing the data and Ms Herrad Frey for reading through the article with a critical eye.

\section{Disclosure}

The authors declare no conflicts of interest in this work.

\section{References}

1. WHO. Obesity: Preventing and Managing the Global Epidemic. WHO Technical report Series 894. Genf: WHO; 2000.

2. Finucane MM, Stevens GA, Cowan MJ, et al. National, regional, and global trends in body-mass index since 1980: systematic analysis of health examination surveys and epidemiological studies with 960 country-years and 9.1 million participants. Lancet. 2011;377(9765): 557-567.

3. Poobalan AS, Aucott LS, Smith WC, Avenell A, Jung R, Broom J. Long-term weight loss effects on all cause mortality in overweight/ obese populations. Obes Rev. 2007;8(6):503-513.

4. Blaine BE, Rodman J, Newman JM. Weight loss treatment and psychological well-being: a review and meta-analysis. J Health Psychol. 2007;12(1):66-82.

5. Management of obesity in adults: project for European primary care. Int J Obes Relat Metab Disord. 2004;28:S226-S231.

6. Deutsche Gesellschaft für Allgemein- und Viszeralchirurgie [German Society for General and Visceral Surgery], Deutsche AdipositasGesellschaft [German Obesity Society], Deutsche Gesellschaft für Psychosomatische Medizin und Psychotherapie [German Society of Psychosomatic Medicine and Psychotherapy], Deutsche Gesellschaft für Ernährungsmedizin [German Society for Nutritional Medicine]. S3-Leitlinie: Chirurgie der Adipositas [Evidence-based German $\mathrm{S} 3$-guidelines for surgery for obesity]. Available at: http://www. adipositas-gesellschaft.de/index.php?id=9. Accessed February 08, 2012. German.

7. Hauner H, Buchholz G, Hamann A, et al. Evidenzbasierte Leitlinie: Prävention und Therapie der Adipositas [Evidence-based guideline for prevention and treatment of obesity]. Available at: http://www.adipositasgesellschaft.de/index.php?id=9. Accessed February 08, 2012. German.

8. Hauner H, Wechsler JG, Kluthe R, Liebermeister, et al. Qualitätskriterien für ambulante Adipositasprogramme. Eine gemeinsame Initiative der Deutschen Adipositas-Gesellschaft, Deutschen Akademie für Ernährungsmedizin, Deutschen Gesellschaft für Ernährung, Deutschen Gesellschaft für Ernährungsmedizin [Quality criteria for ambulatory therapy programs for obesity. A common initiative of the German Obesity Society, German Academy for Nutritional Medicine, German Nutrition Society, German Society for Nutritional Medicine]. Adipositas. 2000;10(19):5-8. German.

9. Berg A, Frey I, König D, Predel HG. Bewegungsorientierte Schulung für adipöse Erwachsene: Ergebnisse zum Interventionsprogramm M.O.B.I.L.I.S. [Exercise-based lifestyle intervention in obese adults: results of the intervention study M.O.B.I.L.I.S.] Dtsch Arztebl Int. 2008;105(11):197-203. German.

10. Weisbrod B. Evaluation eines langfristigen, interdisziplinären Programms zur Gewichtsreduktion bei Adipositas (ADIPOSITIV) [Evaluation of a long-term, interdisciplinary weight reduction program on obesity (ADIPOSITIV)]. PhD dissertation, Department of Medicine, Universität Würzburg; 2003. German.

11. Scholz GH, Flehming G, Scholz M, et al. Evaluation des DGESelbsthilfeprogramms "ICH nehme ab." Gewichtsverlust, Ernährungsmuster und Akzeptanz nach einjähriger beratergestützter Intervention bei übergewichtigen Personen [Evaluation of the DGE self-help program "I lose weight." Weight reduction, eating habits, and acceptance in overweight persons after one year of advisor-supported intervention]. Ernährungs-Umschau. 2005;52(6): 226-231. German.
12. Andersson I, Rössner S. Weight development, drop-out pattern and changes in obesity-related risk factors after two years treatment of obese men. Int J Obes Relat Metab Disord. 1997;21(3):211-216.

13. Inelmen EM, Toffanello ED, Enzi G, et al. Predictors of drop-out in overweight and obese outpatients. Int J Obes (Lond). 2005;29(1): $122-128$.

14. Benecke A. Adipositas - eine therapeutische Herausforderung [Obesity - a therapeutic challenge]. Verhaltenstherapie und Psychosoziale Praxis. 2003;35(4):729-742.

15. Wirth A. Adipositas. Berlin, Heidelberg, New York: Springer; 1997.

16. Günther K, Vollmuth J, Weissbach R, Hohenberger W, Husemann B, Horbach T. Weight reduction after an early version of the open gastric bypass for morbid obesity: results after 23 years. Obes Surg. 2006;16(3): 288-296.

17. Sjostrom L, Lindroos AK, Peltonen M, et al. Lifestyle, diabetes, and cardiovascular risk factors 10 years after bariatric surgery. N Engl J Med. 2004;351(26):2683-2693.

18. Ayyad C, Andersen T. Long-term efficacy of dietary treatment of obesity: a systematic review of studies published between 1931 and 1999. Obes Rev. 2000;1(2):113-119.

19. Goodrick GK, Foreyt JP. Why treatments for obesity don't last. $J$ Am Diet Assoc. 1991;91(10):1243-1247.

20. Berg T, Zurmeyer EL, Ranneberg T, Schönleben K. Surgical therapy of morbid obesity using an adjustable gastric band. Report of experiences over 2 1/2 years with 71 patients. Med Klin (Munich). 2001;96(4):191-195. German.

21. Bohdjalian A, Langer F, Reza Hoda MA, et al. Surgical treatment of obesity. Wien Med Wochenschr. 2004;154(13-14): 329-333. German.

22. Douketis JD, Macie C, Thabane L, Williamson DF. Systematic review of long-term weight loss studies in obese adults: clinical significance and applicability to clinical practice. Int J Obes (Lond). 2005;29(10): 1153-1167.

23. Dalle Grave R, Calugi S, Molinari E, et al. Weight loss expectations in obese patients and treatment attrition: an observational multicenter study. Obes Res. 2005;13(11):1961-1969.

24. Moroshko I, Brennan L, O'Brien P. Predictors of dropout in weight loss interventions: a systematic review of the literature. Obes Rev. 2011; 12(11):912-934.

25. Nauta H, Hospers H, Jansen A. One-year follow-up effects of two obesity treatments on psychological well-being and weight. Br J Health Psychol. 2001;6(3):271-284.

26. Clark MM, Guise BJ, Niaura RS. Obesity level and attrition: support for patient-treatment matching in obesity treatment. Obes Res. 1995;3(1): 63-64.

27. Honas JJ, Early JL, Frederickson DD, O'Brien MS. Predictors of attrition in a large clinic-based weight-loss program. Obes Res. 2003;11(7): 888-894.

28. Deutsche Gesellschaft für Ernährung eV [German Nutrition Society], Österreichische Gesellschaft für Ernährung [Austrian Nutrition Society], Schweizerische Gesellschaft für Ernährungsforschung [Swiss Society for Nutrition Research], Schweizerische Vereinigung für Ernährung [Swiss Association for Nutrition]. D-A-CH-Referenzwerte für die Nährstoffzufuhr [German-Austrian-Swiss reference values for nutrient intake]. Available at: http://www.dge.de/modules.php?name $=\mathrm{C}$ ontent\&pa=showpage\&pid=3. Accessed February 09, 2012. German.

29. Surwit RS, van, Tilburg MA, Zucker N, et al. Stress management improves long-term glycemic control in type 2 diabetes. Diabetes Care. 2002;25(1):30-34.

30. Riedl A, Ahnis A, Kassner U, Reisshauer A, Steinhagen-Thiessen E, Klapp BF. 1-Jahres-Komplex-Intervention bei adipösen PatientInnen im Rahmen eines integrierten Versorgungsvertrages [1-year complex interventionin obese patients within an integrated medical care contract]. Adipositas. 2010;4:2-7. German.

31. Pudel V, Westenhöfer J. FEV. Fragebogen zum Essverhalten. Göttingen: Hogrefe; 1989.

32. Paul T, Thiel A. EDI-2 Eating Disorder Inventory-2. German edition. Göttingen: Hogrefe Verlag; 2004. 
33. Fliege H, Rose M, Arck P, Levenstein S, Klapp BF. Validierung des "Perceived Stress Questionnaire" (PSQ) an einer deutschen Stichprobe [Validation of the "Perceived Stress Questionnaire" (PSQ) in a German sample]. Diagnostica. 2001;47(3):510-515. German.

34. Brähler E, Scheer JW, Hinz A. GBB-24 Gießener Beschwerdebogen [GBB-24 Giessen Subjective Complaints List]. Göttingen: Hogrefe Verlag; 2008. German.

35. Tritt K, von Heymann F, Zaudig M, Zacharias I, Sollner W, Loew T. Development of the "ICD-10-Symptom-Rating"(ISR) questionnaire. Z Psychosom Med Psychother. 2008;54(4):409-418. German.

36. Fischer HF, Tritt K, Klapp BF, Fliege H. [Factor structure and psychometric properties of the ICD-10-Symptom-Rating (ISR) in samples of psychosomatic patients.] Psychother Psychosom Med Psychol. 2010; 60(8):307-315. German.

37. Hörhold M, Klapp BF. Testungen der Invarianz und der Hierarchie eines mehrdimensionalen Stimmungsmodells auf der Basis von Zweipunkterhebungen an Patienten- und Studentenstichproben [Testing the invariance and hierarchy of a multidimensional model of mood by means of repeated measurement with student and patient samples]. $Z$ Med Psychol. 1993;2:27-35. German.

38. Löwe B, Spitzer L, Zipfel S, Herzog W. Gesundheitsfragebogen für Patienten. Testmappe mit Fragebögen, Manual, Schablonen, Kurzanleitung und Auswertungsbögen [Prime MD Patient Health Questionnaire]. Karlsruhe: Pfizer GmbH; 2002. German.

39. Ware J, Kosinski M, Dewey J, Gandek B. How to Score und Interpret Single-item Health Status Measures: A Manual for Users of the SF-8TM Health Survey. Boston: Quality Metric, 2001.

40. Scholler G, Fliege H, Klapp BF. Fragebogen zu Selbstwirksamkeit, Optimismus und Pessimismus: Restrukturierung, Itemselektion und Validierung eines Instrumentes an Untersuchungen klinischer Stichproben [Questionnaire for self-efficacy, optimism and pessimism: Reconstruction, selection of items and validation of an instrument by means of examinations of clinical samples]. Psychother Psychosom Med Psychol. 1999;49(8):275-283. German.

41. Schumacher J, Wilz G, Gunzelmann T, Brähler E. The Antonovsky Sense of Coherence Scale. Test statistical evaluation of a representative population sample and construction of a brief scale. Psychother Psychosom Med Psychol. 2000;50(12):472-482. German.

42. Schulz U, Schwarzer R. Soziale Unterstützung bei der Krankheitsbewältigung. Die Berliner Social Support Skalen (BSSS) [Social support in coping with illness: The Berlin Social Support Scales (BSSS)] Diagnostica. 2003;49:73-82. German.
43. Knoll N. Stressbewältigung als Persönlichkeitsprozess: Ältere Menschen bewältigen eine Kataraktoperation [Coping as a personality process: how elderly patients deal with cataract surgery]. Department of Education and Psychology, Freie Universität Berlin; 2002. German.

44. Mayring P. Qualitative Inhaltsanalyse: Grundlagen und Techniken [Qualitative content analysis. Foundations and techniques]. Weinheim: Beltz; 2003. German.

45. Mayring P. Qualitative Inhaltsanalyse [Qualitative content analysis]. In: Flick U, Kardorff EV, Steinke I, editors. Qualitative Forschung [Qualitative research]. Reinbeck: Rowohlt; 2000: 468-475. German.

46. Franz MJ, VanWormer JJ, Crain AL, et al. Weight-loss outcomes: a systematic review and meta-analysis of weight-loss clinical trials with a minimum 1-year follow-up. J Am Diet Assoc. 2007;107(10): 1755-1767.

47. Expert Panel on Detection, Evaluation, and Treatment of High Blood Cholesterol in Adults. Executive Summary of The Third Report of The National Cholesterol Education Program (NCEP) Expert Panel on Detection, Evaluation, And Treatment of High Blood Cholesterol In Adults (Adult Treatment Panel III). JAMA. 2001;285(19): 2486-2497.

48. Grossi E, Dalle Grave R, Mannucci E, et al. Complexity of attrition in the treatment of obesity: clues from a structured telephone interview. Int J Obes (Lond). 2006;30(7):1132-1137.

49. Antony MM, Johnson WG, Carr-Nangle RE, Abel JL. Psychopathology correlates of binge eating and binge eating disorder. Compr Psychiatry. 1994;35(5):386-392.

50. Schulz S, Laessle RG. Associations of negative affect and eating behaviour in obese women with and without binge eating disorder. Eat Weight Disord. 2010;15(4):e287-e293.

51. Specker S, de Zwaan M, Raymond N, Mitchell J. Psychopathology in subgroups of obese women with and without binge eating disorder. Compr Psychiatry. 1994;35(3):185-190.

52. Marcus MD, Smith D, Santelli R, Kaye W. Characterization of eating disordered behavior in obese binge eaters. Int J Eat Disord. 1992;12(3): 249-255.

53. Schröder K. Persönlichkeit, Ressourcen und Bewältigung [Personality, resources, and coping]. In: Schwarzer R, editor. Gesundheitspsychologie. Ein Lehrbuch [Health psychology. A textbook]. Göttingen: Hogrefe; 1997:319-347. German.

54. Laux L, Weber H. Bewältigung von Emotionen [Coping with emotions]. In: Scherer KR, editor. Psychologie der Emotionen [Encyclopedia of psychology: Psychology of emotions]. Göttingen: Hogrefe; 1990:560 612. German.
Patient Preference and Adherence

\section{Publish your work in this journal}

Patient Preference and Adherence is an international, peer-reviewed, open access journal focusing on the growing importance of patient preference and adherence throughout the therapeutic continuum. Patient satisfaction, acceptability, quality of life, compliance, persistence and their role in developing new therapeutic modalities and compounds to

\section{Dovepress}

optimize clinical outcomes for existing disease states are major areas of interest. This journal has been accepted for indexing on PubMed Central. The manuscript management system is completely online and includes a very quick and fair peer-review system. Visit http://www.dovepress.com/ testimonials.php to read real quotes from published authors. 